\title{
FATTY ACIDS PROFILE (GC-FID) AND ANALYTICAL EVALUATION OF CHEMLALI OLIVE OIL ACCORDING TO A COMBINED LABORATORY SCALE ULTRASOUNDS AND MICROWAVE EXTRACTION
}

\author{
Kaouthar KALLEL, ${ }^{\mathrm{a}}$ Ghayth RIGANE, ${ }^{\mathrm{a}, \mathrm{b} *}$ Hanene GHAZGHAZI ${ }^{\mathrm{c}}$ and Ridha BEN SALEM ${ }^{\mathrm{a}}$ \\ ${ }^{\text {a }}$ Laboratory of Organic Chemistry LR17ES08, Faculty of Sciences of Sfax, \\ Chemistry Department, B.P « $1171 » 3038$, Sfax, University of Sfax, Tunisia \\ ${ }^{\mathrm{b}}$ Physic and Chemistry Department, Faculty of Sciences and Technology of Sidi Bouzid, B.P «380», 9100, \\ Sidi Bouzid, University of Kairouan, Tunisia \\ ${ }^{c}$ Laboratory of Management and Valorization of Forest Resources, \\ National Research Institute of Rural Engineering, Water and Forestry (INRGREF), Tunisia
}

\begin{abstract}
The aim of this work was to investigate the possibility of combination between micro-waves and ultra-sounds in order to determinate their impact on quality parameters, antioxidant capacity and phenolic compounds as well as fatty acid composition. The protocol consisted in microwave followed by a sonication treatment of olive paste for 5, 10 and $15 \mathrm{~min}$. Results showed that the total phenolic content of olive oil increased positively with the increasing time of treatment ranging from 356 to $\sim 639 \mathrm{mg}$ GAE. $\mathrm{kg}^{-1}$ of olive oil. On the other hand, the fatty acid profiles of all studied oils were determined by GC-FID. Besides, olive oil obtained after $15 \mathrm{~min}$ of microwave olive past treatment followed by 10 or $15 \mathrm{~min}$ of ultrasound treatment showed that these oils had the highest value of Z-vaccenic $(\mathrm{C} 18: 1 \mathrm{n}-7)+$ Oleic $(\mathrm{C} 18: 1 \mathrm{n}-9)$ acids. These results encourage further developments for a combined continuous microwave and ultrasonic conditioning technology to fasten the olive oil extraction, to enhance total phenolic, chlorophyll as well as carotenoid contents and Fatty acid composition.
\end{abstract}

\section{INTRODUCTION}

The traditional techniques for extracting from olive oil often have constraints such as low yields, time-consuming extraction times and the use of large amounts of solvents. In recent years, numerous alternative techniques to overcome these problems have been developed. Among them, there are emerging microwaves, supercritical fluids, ultrasound or the addition of a co-adjuvant, ${ }^{1-5}$ as well as pulsed electric field, ${ }^{6-8}$ Therefore, ultrasound and microwave have many applications not only in our homes but also in industry. In order to increase the oxidative stability capacities of virgin olive oil (VOO), by reducing the extraction time and increasing the olive oil quality, many researchers teams proposed many studies to improve olive oil performance. ${ }^{6,9}$ The proposed

\footnotetext{
*Corresponding author: gaith.rigane@yahoo.fr; ghayth.rigane@fstsbz.u-kairouan.tn
} 
olive paste treatments based on the use of a heat exchanger (either microwaves by electromagnetic waves or ultrasonic waves by mechanical waves) generally lead to a significant increase in phenols for all the treated pastes, by finally getting better quality products, bioactive and beneficial to health. Therefore, Malheiro et al. ${ }^{10}$ studied the influence of introducing microwaves and ultrasounds on the extraction of olive oil in point of view: oil yields and quality. For example, Yahyaoui et al. ${ }^{4}$ studied the phenolic compounds present in Chemlali and Memlick olive pastes and oils obtained after ultrasound treatment of depitted olive paste and whole olive samples ${ }^{4}$. They found that the first one were the most affected. While, Leone et al. ${ }^{11}$ mentioned that the use of microwaves allows reducing the malaxation time while improving the quality of the olive oil. Therefore, several studies have shown that these physicochemical techniques can reduce the addition of water during the mixing process and subsequently avoid industrial discharges that are not degradable (wastewater) into the environment.

The combined effects of microwaves and ultrasounds on Chemlali olive oil yield and quality were studied. Several analytical methods, legally established, were selected to evaluate the quality of the extra virgin olive oil (EVOO): Extraction yields, quality indexes, total phenols, chlorophylls and carotenoids contents as well as fatty acid composition were determined.

\section{MATERIALS AND METHODS}

\section{Chemicals}

Methanol, $n$-hexane and cyclohexane HPLCgrade solvents were purchased from Riedel-deHaen (Switzerland). Folin-Ciocalteu was obtained from Fluka (Switzerland). The solvents were of appropriate purity. Fatty acid methyl esters (FAMEs) standards were obtained from Sigma Chemical Co. (St. Louis, MO, USA). 2,2-Diphenyl-1picrylhydrazyl (DPPH) and rutin were purchased from Sigma-Aldrich (USA). Gallic acid was purchased from Extrasynthese (Geney, France).

\section{Olive fruit variety}

Chemlali olive fruits were harvested from Sfax (South of Tunisia) during 2018-2019 crop seasons. The olives were ripe with a maturity index equal to
6 according to Agronomic Station of Jaén. ${ }^{12}$ The olives were transported to Organic Chemistry Laboratory LR17ES08 for the paste preparation at the same day.

\section{Samples preparation}

Before crushing Chemlali olive fruits, they were divided in 10 batches ( $2500 \mathrm{~g}$ each batches) have been prepared after removing leaves and washing. After that, each batches has been crushed using a hammer crusher (a stainless-steel hammer mill operating at $3000 \mathrm{rpm}$ provided with a $5 \mathrm{~mm}$ sieve) then nine from 10 obtained olive paste were treated by microwave (DELONGHI, Reference: $533 \mathrm{MW}$, power: 900 watt) for 5, 10 and $15 \mathrm{~min}$. After that, each treated olive paste has been subjected to an ultrasound treatment (Elmasonic $\mathrm{S} 60 \mathrm{H}$ ultrasonic bath) for 5,10 , and $15 \mathrm{~min}$. On the other hand, olive oil has been extracted from the first obtained olive paste (served as a control sample).

Each obtained olive paste was malaxed for $15 \mathrm{~min}$ and oil extraction has been obtained as it was described before by Yahyaoui et al. ${ }^{4}$ In Table 1 , the temperature of the olive paste was measured immediately after ultrasound exposure, by inserting a thermocouple (K-type; Ni/Al-Ni/Cr) connected to an acquisition system (HI 98804, Hanna Instrument, Villafranca Padovana-PD, Italy) at approximately the geometrical centre of the sample. Finally, the obtained olive oils were stored in black glass bottles and kept in a cold room at $+4{ }^{\circ} \mathrm{C}$ until further use. ${ }^{4}$

\section{Extraction of phenolic fraction from olive oil}

The phenolic extracts were obtained following the procedure of Yahyaoui et al. ${ }^{4}$ with some modifications. Briefly, the oil sample $(4 \mathrm{~g})$ was added to $2 \mathrm{~mL}$ of $n$-hexane and $4 \mathrm{~mL}$ of a methanol/water $(80: 20, \mathrm{v} / \mathrm{v})$ solution in a $20 \mathrm{~mL}$ centrifuge tube. After vigorous mixing, they were centrifuged for $3 \mathrm{~min}(6000 \mathrm{rpm})$. The hydroalcoholic phase was collected and the hexanic phase was re-extracted twice with $4 \mathrm{~mL}$ of methanol/water $(80: 20, \mathrm{v} / \mathrm{v})$ solution each time. Finally, the hydroalcoholic fractions were combined, washed with $4 \mathrm{~mL}$ of $n$-hexane to remove the residual oil. After the evaporation of hydroalcoholic extract to dryness; the residue was stored in glass at $0{ }^{\circ} \mathrm{C}$ in the dark until its use. 
Table 1

Quality indices of olive oil samples from Chemlali cultivar

\begin{tabular}{|c|c|c|c|c|c|c|c|c|c|c|}
\hline & S0M0U0 & S1M5U5 & S2M5U10 & S3M5U15 & S4M10U5 & S5M10U10 & S6M10U15 & S7M15U5 & S8M15U10 & S9M15U15 \\
\hline $\begin{array}{l}\mathrm{T}^{\circ}(\mathrm{C}) \text { after ultraound } \\
\text { treatment }\end{array}$ & $17.9 \pm 0.4^{\mathrm{a}}$ & $16.2 \pm 0.4^{\mathrm{a}}$ & $17.6 \pm 0.4^{\mathrm{a}}$ & $17.0 \pm 0.4^{\mathrm{a}}$ & $16.8 \pm 0.4^{\mathrm{a}}$ & $17.5 \pm 0.4^{\mathrm{a}}$ & $18.1 \pm 0.4^{\mathrm{a}}$ & $18.9 \pm 0.4^{\mathrm{a}}$ & $18.0 \pm 0.4^{\mathrm{a}}$ & $18.0 \pm 0.4^{\mathrm{a}}$ \\
\hline $\begin{array}{l}\text { Free acidity ( } \% \text { oleic } \\
\text { acid) }\end{array}$ & $0.22 \pm 0.01^{\mathrm{a}}$ & $0.4 \pm 0.00^{\mathrm{a}}$ & $0.3 \pm 0.00^{\mathrm{b}}$ & $0.2 \pm 0.00^{\mathrm{c}}$ & $0.2 \pm 0.00^{\mathrm{c}}$ & $0.3 \pm 0.00^{\mathrm{b}}$ & $0.3 \pm 0.00^{\mathrm{b}}$ & $0.1 \pm 0.00^{\mathrm{d}}$ & $0.1 \pm 0.00^{\mathrm{d}}$ & $0.1 \pm 0.00^{\mathrm{d}}$ \\
\hline $\mathrm{PV}$ (meq $\mathrm{O}_{2} / \mathrm{kg}$ oil) & $6.52 \pm 0.32^{\mathrm{a}}$ & $5.64 \pm 0.09^{\mathrm{a}}$ & $2.82 \pm 0.04^{\mathrm{b}}$ & $2.82 \pm 0.06^{\mathrm{b}}$ & $2.82 \pm 0.04^{\mathrm{b}}$ & $2.82 \pm 0.00^{\mathrm{b}}$ & $2.82 \pm 0.01^{\mathrm{b}}$ & $2.82 \pm 0.02^{\mathrm{b}}$ & $2.82 \pm 0.04^{\mathrm{b}}$ & $2.82 \pm 0.05^{\mathrm{b}}$ \\
\hline $\mathrm{K}_{232}$ & $0.04 \pm 0.00^{\mathrm{a}}$ & $0.14 \pm 0.09^{\mathrm{a}}$ & $0.26 \pm 0.00^{\mathrm{b}}$ & $0.22 \pm 0.04^{\mathrm{b}}$ & $0.28 \pm 0.00^{\mathrm{c}}$ & $0.16 \pm 0.06^{\mathrm{a}}$ & $0.08 \pm 0.00^{\mathrm{d}}$ & $0.19 \pm 0.00^{\mathrm{a}}$ & $0.13 \pm 0.06^{\mathrm{a}}$ & $0.18 \pm 0.00^{\mathrm{a}}$ \\
\hline $\mathrm{K}_{270}$ & $2.00 \pm 0.10^{\mathrm{a}}$ & $0.02 \pm 0.00^{\mathrm{a}}$ & $0.02 \pm 0.00^{\mathrm{a}}$ & $0.04 \pm 0.00^{\mathrm{b}}$ & $0.05 \pm 0.00^{\mathrm{c}}$ & $0.02 \pm 0.00^{\mathrm{a}}$ & $0.01 \pm 0.00^{\mathrm{d}}$ & $0.02 \pm 0.00^{\mathrm{a}}$ & $0.01 \pm 0.00^{\mathrm{d}}$ & $0.02 \pm 0.00^{\mathrm{a}}$ \\
\hline $\begin{array}{l}\text { Chlorophyll content } \\
\text { (mg/kg of oil) }\end{array}$ & $1.63 \pm 0.01^{\mathrm{a}}$ & $1.63 \pm 0.01^{\mathrm{a}}$ & $1.46 \pm 0.08^{b}$ & $1.30 \pm 0.05^{\mathrm{ab}}$ & $0.55 \pm 0.04^{\mathrm{c}}$ & $1.14 \pm 0.01^{\mathrm{bc}}$ & $2.20 \pm 0.07^{\mathrm{d}}$ & $6.39 \pm 0.004^{\mathrm{e}}$ & $7.21 \pm 0.00^{\mathrm{f}}$ & $3.86 \pm 0.00^{\mathrm{de}}$ \\
\hline $\begin{array}{l}\text { Carotenoid content } \\
\text { (mg/kg of oil) }\end{array}$ & $1.00 \pm 0.00^{\mathrm{a}}$ & $0.22 \pm 0.00^{\mathrm{a}}$ & $0.49 \pm 0.00^{\mathrm{b}}$ & $0.36 \pm 0.05^{\mathrm{ab}}$ & $0.36 \pm 0.00^{\mathrm{ab}}$ & $0.33 \pm 0.05^{\mathrm{ab}}$ & $0.62 \pm 0.05^{\mathrm{c}}$ & $0.94 \pm 0.05^{\mathrm{d}}$ & $1.83 \pm 0.05^{\mathrm{e}}$ & $1.10 \pm 0.00^{\mathrm{de}}$ \\
\hline TPC (mg GAE/kg of oil) & $225 \pm 0.00^{\mathrm{a}}$ & $356 \pm 0.00^{\mathrm{a}}$ & $387 \pm 0.00^{\mathrm{b}}$ & $395 \pm 0.1^{\mathrm{c}}$ & $562 \pm 0.50^{\mathrm{d}}$ & $580 \pm 0.6^{\mathrm{e}}$ & $603 \pm 0.80^{\mathrm{f}}$ & $622 \pm 0.0^{\mathrm{j}}$ & $632 \pm 0.20^{\mathrm{h}}$ & $638 \pm 0.70^{\mathrm{i}}$ \\
\hline $\mathrm{TFC}(\mathrm{mg} \mathrm{RE} / \mathrm{kg}$ of oil) & $75 \pm 0.80^{\mathrm{a}}$ & $50 \pm 0.80^{\mathrm{a}}$ & $76 \pm 0.80^{b}$ & $123 \pm 0.5^{\mathrm{c}}$ & $182 \pm 0.60^{\mathrm{d}}$ & $197 \pm 0.4^{\mathrm{e}}$ & $203 \pm 0.00^{\mathrm{f}}$ & $214 \pm 0.7^{\mathrm{j}}$ & $246 \pm 0.60^{\mathrm{h}}$ & $257 \pm 0.40^{\mathrm{i}}$ \\
\hline $\mathrm{IC}_{50}(\mathrm{~g} / \mathrm{l})$ & $1.24 \pm 0.06^{\mathrm{a}}$ & $0.8 \pm 0.06^{\mathrm{a}}$ & $0.8 \pm 0.02^{\mathrm{a}}$ & $0.4 \pm 0.06^{\mathrm{c}}$ & $0.1 \pm 0.08^{\mathrm{d}}$ & $0.1 \pm 0.03^{\mathrm{d}}$ & $0.1 \pm 0.010^{\mathrm{d}}$ & $0.1 \pm 0.01^{\mathrm{d}}$ & $0.08 \pm 0.00^{\mathrm{e}}$ & $0.04 \pm 0.00^{\mathrm{f}}$ \\
\hline
\end{tabular}

Results were expressed as mean \pm standard deviation of 3 determinations. Different letters for the same line indicate significant differences among varieties $(p<0.05)$

TPC: Total Phenolic content, TFC: Total Flavonoid content.

$\mathrm{S}_{\mathrm{i}}$ : Sample with i means the number of each sample ranged from 1 to 9

$\mathrm{M}_{\mathrm{j}}$ : Microwave treatment time with $\mathrm{j}$ means the microwave treatment time expressed in min

$\mathrm{U}_{\mathrm{k}}$ : Ultrasound treatment time with $\mathrm{k}$ means the ultrasound treatment time expressed in min

SOM0U0 served as a control 


\section{Total phenolic and flavonoid contents}

The concentration of total phenolic compounds in extracts was evaluated using the Folin-Ciocalteu reagent. Briefly, $50 \mu \mathrm{L}$ aliquot of extract was assayed with $250 \mu \mathrm{L}$ of phenol reagent and $500 \mu \mathrm{L}$ of aqueous sodium carbonate $(20 \%, \mathrm{w} / \mathrm{v})$. The mixture was vortexed and diluted with water to a final volume of $5 \mathrm{~mL}$. After incubation for $30 \mathrm{~min}$ at room temperature, the absorbance was measured at $765 \mathrm{~nm}$. For the gallic acid, the curve absorbance versus concentration was described by the equations: $\mathrm{y}=5.844 \mathrm{x}\left(\mathrm{r}^{2}=0.9184\right)$. TPC was expressed as $\mathrm{mg}$ gallic acid equivalents per $\mathrm{kg}$ of oil. ${ }^{13}$

On the other hand, total flavonoid content (TFC) was determined spectrophotometrically according to Rigane et al., ${ }^{13}$ using a method based on the formation of complex flavonoid aluminium, having the maximum absorption at $510 \mathrm{~nm}$. For the rutin, the curve absorbance versus concentration was described by the equations: $y=48.42 \mathrm{x}-0.045$ $\left(\mathrm{r}^{2}=0.975\right)$. TFC was expressed as $\mathrm{mg}$ of the rutin equivalent per $\mathrm{kg}$ of oil. All determinations were performed in triplicates.

\section{Analytical methods}

Free acid, peroxide value and specific extinction at 232 and $270 \mathrm{~nm}$ parameters. The determination of these indices was carried out following the International Olive Council (IOC) methods. ${ }^{14}$

Chlorophyll and carotenoid content. The chlorophyll and carotenoid contents ( $\mathrm{mg} / \mathrm{kg}$ of oil) were determined in cyclohexane. These parameters were then analyzed using a UV-Vis spectrophotometer (Lasany Model I-290) at $670 \mathrm{~nm}$ and $470 \mathrm{~nm}$ for chlorophyll and carotenoid, ${ }^{15}$ respectively.

\section{Fatty acid composition analysis}

About $120 \mathrm{mg}$ of olive oil in isooctane $(2 \mathrm{~mL})$ was transmethylated with a cold solution of $\mathrm{KOH}$ (2 M) $(0.2 \mathrm{~mL})$ according to the EEC $2568 / 1991$ (1991). ${ }^{16}$ Fatty acid methyl esters (FAMEs) were analyzed according to the EEC 2568/1991 (1991). ${ }^{16}$ Analyses were performed on a Hewlett Packard 6890 gaz chromatography using a capillary column (stabilwax, Restek,length $50 \mathrm{~m}$, internal diameter $0.32 \mathrm{~mm}$ and film thickness $0.25 \mu \mathrm{m})$. The column temperature was isothermal at $180{ }^{\circ} \mathrm{C}$ and the injector $230{ }^{\circ} \mathrm{C}$ and detector temperatures were $250{ }^{\circ} \mathrm{C}$. Fatty acids were identified by comparing retention times $\left(T_{R}\right.$ expressed in min) with standard compounds. Fatty acids percentages were determined by internal standardization without taking into account the mass response factors. The coefficients of variation in Fatty acids percentages were $<5 \%$ for the most important FAMEs and $<10 \%$ for some minor ones. The identified Fatty acids were: myristic $(14: 0) \quad\left(T_{R}=8.341 \mathrm{~min}\right)$, palmitic $(16: 0)$ $\left(\mathrm{T}_{\mathrm{R}}=10.648 \mathrm{~min}\right)$, hypogeic $(16: 1 \mathrm{n}-9)+$ palmitoleic $(16: 1 \mathrm{n}-7)\left(\mathrm{T}_{\mathrm{R}}=11.070 \mathrm{~min}\right)$, stearic $(18: 0)\left(\mathrm{T}_{\mathrm{R}}=\right.$ $13.637 \mathrm{~min})$, oleic $(18: 1 \mathrm{n}-9)+\mathrm{Z}$-vaccenic $(18: 1 \mathrm{n}$ 7) $\left(\mathrm{T}_{\mathrm{R}}=14.127\right.$ and $14.203 \mathrm{~min}$, respectively $)$, linoleic $(18: 2)\left(\mathrm{T}_{\mathrm{R}}=14.925 \mathrm{~min}\right)$, linolenic $(18: 3)$ $\left(\mathrm{T}_{\mathrm{R}}=15.976 \mathrm{~min}\right)$, arachidic $(20: 0)\left(\mathrm{T}_{\mathrm{R}}=17.084\right.$ min), gadoleic $(20: 1)\left(T_{R}=17.572 \mathrm{~min}\right)$, behenic $(22: 0)\left(T_{R}=20.832 \mathrm{~min}\right)$ and lignoceric $(24: 0)$ $\left(\mathrm{T}_{\mathrm{R}}=24.658 \mathrm{~min}\right)$ acids.

\section{Antioxidant activity evaluation}

The antioxidant activity of chemlali olive oils towards DPPH radical was determined according to the method of Rigane et al.. ${ }^{17}$ Radical scavenging activity, expressed as percent inhibition, was calculated by the following formula:

Percent radical scavenging activity $=$

$=($ control OD - sample OD / control OD $) \times 100$

OD: Optical density

\section{Statistical analysis}

Results of descriptive analyses are expressed as mean and standard deviation (SD). Statistical differences were calculated using a one-way analysis of variance (ANOVA), employing the Student's $t$-test. Differences were considered significant at $p<0.05$.

\section{RESULTS AND DISCUSSION}

\section{Effect of microwave \\ and ultrasound combination treatment on FA and PV parameters}

Free acidity is an index that determines quality parameters of olive oil from an analytical point of view. ${ }^{18}$ It should be noted that extra virgin olive oil should have a maximum free acidity, expressed in oleic acid, of $0.8 \% .{ }^{19}$ From Table 1 , the obtained values varied between 0.1 and $0.3 \%$ and consequently did not exceed the limits announced 
for EVOO. Therefore, we concluded that the treatment of olive paste by microwave followed by ultrasound do not affect hydrolysis reactions of triglycerides present in the obtained olive oil. The obtained results were in agreement with Tamborrino et al. ${ }^{6}$ and Gila et al. ${ }^{8}$ who mentioned that there were no significant difference observed for free acidity between olive pastes conditioned using the microwave-assisted as well as ultrasound treatment, and olive paste traditionally treated. While Rigane et al. ${ }^{20}$ found a significant decrease in all free acidity values for Chemlali and Memlick olive oils, when they investigated the change in some quality parameters and oxidative stability of olive oils with regard to ultrasound pretreatment, depitting and water addition.

Our research team examined the peroxide values of the obtained olive oils, we found that in all experiments, olive oils displayed lower peroxide indexes $\left(2.82<\mathrm{PV}<5.64 \mathrm{meq} \mathrm{O}_{2} / \mathrm{kg}\right.$ oil $)$ than those obtained with the traditional methods. Therefore, as observed, the values of these quality parameters show that the combination between microwave and sonication did not degrade the oils. According to these quality parameters, all oils were classified in the 'extra virgin' category as established by EU regulation. ${ }^{19}$

As found by our research team, Jimenez et al., ${ }^{21}$ Clodoveo et al. ${ }^{22}$ and Gila et al. ${ }^{8}$ claimed that ultrasonic treatment do not affect a significant modification on the parameters analyzed before. In another study made by Rigane et al., ${ }^{20}$ who declared that Chemlali and Memlick oils PV parameter showed significant differences during ultrasound treatment times. While, Tamborrino et al. ${ }^{6}$ claimed that the effect of microwaves could certainly be attributed to weak contact with atmospheric oxygen during malaxation, which prevents lipid auto-oxidation reactions resulting from peroxide formation decrease.

\section{Molar Absorptivity}

$\mathrm{K}_{232}$ and $\mathrm{K}_{270}$ are measured from absorptions at 232 and $270 \mathrm{~nm}$ respectively, with a UV spectrophotometer by dissolving the sample in cyclohexane. These molar absorptivities were quantified to determine the presence of conjugated diene and triene systems resulting from oxidation processes $^{23}$. All samples showed very low values of $0.13<\mathrm{K}_{232}<0.26$ and $0.01<\mathrm{K}_{270}<0.05$, therefore, the obtained oils were belonging to EVOOs. Considering these parameters, no significant differences were found $(p<0.05)$. These results were in accordance with data reported by Malheiro et al., ${ }^{10}$ Clodoveo et al. ${ }^{22}$ and Gila et al. ${ }^{8}$

\section{Chlorophyll and Carotenoids contents}

Olive oil contains minor compounds that give it its organoleptic and nutritional qualities. Among these minor compounds, pigments, due to their antioxidant characteristics in obscurity and prooxidant ones in light, seem to play an important role in the stability of oxidation in the olive oil during storage and in the preservation of its quality. ${ }^{24}$ The levels of $1.63-7.21 \mathrm{mg} \mathrm{kg}^{-1}$ and $0.22-1.83 \mathrm{mg} \mathrm{kg}^{-1}$ for chlorophylls and carotenes were observed, respectively. These levels were influenced by the olive extraction methods. On the other hand, S8M15U10 and S9M15U15 oil samples were characterized by a carotenoid content more than 1 ppm (Table 1) which allowed this compound to be consumed as an antioxidant during olive oil storage ${ }^{23,25}$. Furthermore, pigment contents were lower than that obtained from similar Tunisian (Oueslati and Chemchali), introduced Spanish and Italian oils (Arbequina and Leccino), which were characterized by their high pigments levels. ${ }^{24}$ According to Gila et $a l^{8}{ }^{8}$ the ultrasound treatment, after $0,15,30$ and $60 \mathrm{~min}$ of treatment, did not affect the pigment content in the oils studied, thus no degradation process were caused due to the application of this emerging technology.

\section{Phenolic and flavonoid contents}

As shown in Table 1, the TPC in Chemlali olive oil varied between 356 to $\sim 639 \mathrm{mg} \mathrm{GAE} / \mathrm{kg}$ of oil. Many authors reported that the TPC in some Tunisian virgin olive oils ranged between 150 and $700 \mathrm{mg} \mathrm{kg}^{-1}$ of oil. ${ }^{23,26}$ The highest concentration of phenolic compounds was obtained after treatment with microwave for $15 \mathrm{~min}$ followed by $15 \mathrm{~min}$ of ultrasound treatment ( $639 \mathrm{mg} \mathrm{GAE} / \mathrm{kg}$ of olive oil). The same tendency was observed in the content of flavonoids. These results were higher than those obtained by traditional extraction methods during three crop seasons (2004-2005, 2005-2006, 2006-2007). ${ }^{26}$ In addition, Jimenez et al. ${ }^{21}$ mentioned that total phenolic compounds present in Picual olive oil values obtained from olive paste treated with ultrasound were between $349 \pm 30$ and $273 \pm 2 \mathrm{ppm}$ in two harvested time. While, Yahyaoui et al. ${ }^{4}$ claimed that total phenol content in Chemlali and Memlick olive oil increased by increasing at the time of ultraound 
treatment. Furthermore, Gila et al. ${ }^{8}$ declared that phenolic content was not affected by the ultrasound treatments, although a slight tend to decrease could be observed in US treated "Arbequina" oils that could be explained by the slight increase of the temperature during the US treatment. On the other hand, Di Giovacchino et $a l .{ }^{27}$ published that the rise in phenolic content level is probably assigned to different mechanisms exerted by microwave treatment. One of which consists of the inhibition of polyphenol oxydase, an enzyme which decomposes phenolic compounds. This requires a high level on microwave in order to break the cellular structure, inhibit polyphenol oxydase activity and enable phenolic compounds migration to the oily phase.

Taking into account of these data, we have demonstrated that the extraction technique might affect total phenolic content concentration in olive oil.

\section{Antioxydant Capacities}

The results of the free radical scavenging properties of all olive oils studied evaluated by the DPPH method was summarized in Table 1. From these results, we can conclude that extraction technique is one of the factors affecting the antioxidant activity of oil. As shown in Table 1, the DPPH scavenging activity of oil obtained by S9M15U15 was found to be higher and significantly $(p<0.05)$ different than that of oils obtained by different treatment period. This high stability could be explained by the higher contents of total phenols.

\section{Fatty acids composition}

The main fatty acid profiles and their levels of both studied oils are shown in Table 2 and Figure 1. Thirteen fatty acids were identified and quantified. The results showed that the fatty acid composition varied considerably depending on the Chemlali olive paste treatments. As expected, the major fatty acids found in all samples are Oleic $(18: 1 n-9)+Z$-vaccenic $(18: 1 n-7)$ acids and is present in higher concentrations (54.97-63.19\%) than other fatty acids. Its content in S4M10U5 was the lowest $(54.97 \%$ ) (Table 2). As reported by EEC (2003), ${ }^{19}$ the oleic acid percentage varied from 55 to $83 \%$ in the EVOO. These percentages are close to those of many Tunisian olive oil cultivars such as: Chétoui, Chemlali, Dhokar,
Gemri-Dhokar and Chemlali-Tataouine which were extracted by mechanical method. ${ }^{23,26}$

From Table 2, we can observe a significant differencein the linoleic acid (C18:2) levels $(p<0.05)$. The highest percentage was observed in olive oil extracted from Chemlali olive paste after 5 min of treatment by microwaves followed by 5 min ultrasounds $(\mathrm{C} 18: 2=19.70 \%)$. In addition, our research team mentioned that in all studied olive oil, the linoleic acid level do not exceed limit fixed by the norm $(21 \%){ }^{19}$. On the other hand, palmitic acid level varied from 12.64 to $20.12 \%$. The high palmitic acid level was quantified in the olive oil extracted after $15 \mathrm{~min}$ of microwave followed by $5 \mathrm{~min}$ of ultrasound olive paste treatment which makes this oil freezes at a low temperature. In addition, small amounts of hypogeic $(16: 1 n-9)+$ palmitoleic $(16: 1 n-7)$, stearic (C18:0), linolenic (C18:3) and arachidic (C20:0), Gadoleic (C20:1), Behenic (C22:0), Lignoceric (C24:0) acids where present which with different percentage of oil samples. Levels of these fatty acids in the two tested oils are close to the EEC established limits. ${ }^{19}$ The $\mathrm{C} 18: 1 / \mathrm{C} 18: 2$ ratio was known as a good indicator of the relationship with stability. Our results had a ratio lower than 7 which is the minimum value proposed by Kiritsakis et $a .^{28}$ Fatty acid composition of Chemlali oil obtained using new technological extraction methods was similar to those reported for Zarrazi Douirat, Chemlali-Tatouin and Fakhari Douirat (Tunisian olive oil from Tataouin zone), which were obtained by classical extraction method, i.e. a high level of oleic acid and a low palmitic and linoleic acid content. ${ }^{23,26}$

It was observed that Chemlali olive oil obtained after $15 \mathrm{~min}$ of microwave followed by and $10 \mathrm{~min}$ ultrasound treatments was poor in SFA (15.89\%), essentially due to its low content in palmitic acid, which represents the major acid of the saturated fatty acid fraction. In addition, the oil obtained with those conditions is rich in MUFA $=64.86 \%$ and consequently, on UFA $=84.21 \%$, due to its high content in oleic acid.

In general, and regarding to the effect of combination between microwave and sonication on fatty acids composition, significant differences $(p<$ 0.05 ) were found between untreated and M+US treated samples without breakdown of fatty acid carbon chains. These results were not in accordance with those reported by Gila and co-workers, ${ }^{8}$ who claimed that the ultrasound application $(40 \mathrm{kHz})$ does not affect to the lipid profile of «Arbequina» and «Picual » virgin olive oils. 
Table 2

Fatty acid composition of virgin olive oil samples

\begin{tabular}{|c|c|c|c|c|c|c|c|c|c|c|}
\hline & S0M0U0 & S1M5U5 & S2M5U10 & S3M5U15 & S4M10U5 & S5M10U10 & S6M10U15 & S7M15U5 & S8M15U10 & S9M15U15 \\
\hline Myristic acid (C14:0) & $0.021 \pm 0.00^{\mathrm{a}}$ & $0.021 \pm 0.00^{\mathrm{a}}$ & $0.022 \pm 0.00^{\mathrm{b}}$ & $0.020 \pm 0.00^{\mathrm{c}}$ & $0.01 \pm 0.00^{\mathrm{d}}$ & $0.010 \pm 0.00^{\mathrm{d}}$ & $0.020 \pm 0.00^{\mathrm{c}}$ & $0.020 \pm 0.00^{\mathrm{c}}$ & $0.010 \pm 0.00^{\mathrm{d}}$ & $0.018 \pm 0.00^{\mathrm{e}}$ \\
\hline Palmitic acid (C16:0) & $13.95 \pm 0.10^{\mathrm{a}}$ & $18.92 \pm 0.06^{\mathrm{b}}$ & $19.80 \pm 0.01^{\mathrm{c}}$ & $19.01 \pm 0.02^{\mathrm{ab}}$ & $19.60 \pm 0.04^{\mathrm{ab}}$ & $19.50 \pm 0.06^{\mathrm{ab}}$ & $18.86 \pm 0.08^{\mathrm{a}}$ & $20.12 \pm 0.00^{\mathrm{d}}$ & $12.64 \pm 0.01^{\mathrm{e}}$ & $18.58 \pm 0.00^{\mathrm{f}}$ \\
\hline $\begin{array}{c}\text { Hypogeic }(\mathrm{C} 16: 1 \mathrm{n}-9) \\
+ \text { palmitoleic } \\
(\mathrm{C} 16: 1 \mathrm{n}-7) \text { acids }\end{array}$ & $1.20 \pm 0.01^{\mathrm{a}}$ & $2.25 \pm 0.03^{b}$ & $2.41 \pm 0.06^{\mathrm{c}}$ & $2.32 \pm 0.08^{\mathrm{bc}}$ & $2.37 \pm 0.04^{\mathrm{bc}}$ & $2.39 \pm 0.08^{\mathrm{bc}}$ & $2.27 \pm 0.05^{\mathrm{bc}}$ & $2.42 \pm 0.00^{\mathrm{d}}$ & $1.45 \pm 0.02^{\mathrm{e}}$ & $2.25 \pm 0.00^{\mathrm{f}}$ \\
\hline Stearic acid (C18:0) & $4.05 \pm 0.30^{\mathrm{a}}$ & $2.31 \pm 0.01^{\mathrm{b}}$ & $2.26 \pm 0.04^{\mathrm{b}}$ & $2.31 \pm 0.03^{\mathrm{c}}$ & $2.28 \pm 0.09^{b}$ & $2.30 \pm 0.04^{\mathrm{bc}}$ & $1.61 \pm 0.07^{\mathrm{d}}$ & $2.2 \pm 0.06^{\mathrm{b}}$ & $2.60 \pm 0.09^{\mathrm{e}}$ & $1.87 \pm 0.06^{\mathrm{f}}$ \\
\hline $\begin{array}{c}\text { Z-vaccenic }(\mathrm{C} 18: 1 \mathrm{n}-7)+ \\
\text { Oleic }(\mathrm{C} 18: 1 \mathrm{n}-9) \text { acids }\end{array}$ & $68.39 \pm 0.01^{\mathrm{a}}$ & $55.26 \pm 0.01^{\mathrm{b}}$ & $55.06 \pm 0.02^{\mathrm{c}}$ & $55.57 \pm 0.04^{\mathrm{d}}$ & $54.97 \pm 0.09^{\mathrm{c}}$ & $56.07 \pm 0.05^{\mathrm{e}}$ & $57.13 \pm 0.09^{\mathrm{f}}$ & $55.32 \pm 0.00^{\mathrm{bd}}$ & $63.19 \pm 0.09^{\mathrm{g}}$ & $57.79 \pm 0.00^{\mathrm{h}}$ \\
\hline Linoleic acid (C18:2) & $19.00 \pm 0.07^{\mathrm{a}}$ & $19.70 \pm 0.07^{\mathrm{b}}$ & $18.99 \pm 0.09^{\mathrm{c}}$ & $19.28 \pm 0.06^{\mathrm{bc}}$ & $19.30 \pm 0.01^{\mathrm{bc}}$ & $18.24 \pm 0.01^{\mathrm{d}}$ & $18.57 \pm 0.02^{\mathrm{cd}}$ & $18.49 \pm 0.05^{\mathrm{cd}}$ & $18.61 \pm 0.09^{\mathrm{cd}}$ & $18.00 \pm 0.04^{\mathrm{e}}$ \\
\hline Linolenic acid (C18:3) & $0.60 \pm 0.04^{\mathrm{a}}$ & $0.69 \pm 0.04^{\mathrm{b}}$ & $0.69 \pm 0.00^{\mathrm{b}}$ & $0.68 \pm 0.05^{\mathrm{b}}$ & $0.69 \pm 0.04^{\mathrm{b}}$ & $0.69 \pm 0.00^{\mathrm{b}}$ & $0.68 \pm 0.05^{\mathrm{b}}$ & $0.66 \pm 0.03^{\mathrm{b}}$ & $0.67 \pm 0.04^{\mathrm{b}}$ & $0.68 \pm 0.03^{\mathrm{b}}$ \\
\hline Arachidic acid (C20:0) & $0.23 \pm 0.01^{\mathrm{a}}$ & $0.42 \pm 0.01^{\mathrm{b}}$ & $0.38 \pm 0.02^{\mathrm{c}}$ & $0.41 \pm 0.00^{\mathrm{d}}$ & $0.40 \pm 0.01^{\mathrm{d}}$ & $0.37 \pm 0.09^{\mathrm{e}}$ & $0.42 \pm 0.00^{\mathrm{f}}$ & $0.37 \pm 0.00^{\mathrm{e}}$ & $0.48 \pm 0.02^{\mathrm{e}}$ & $0.40 \pm 0.03^{\mathrm{bc}}$ \\
\hline Gadoleic acid (C20: $1 \mathrm{n} 9)$ & $0.21 \pm 0.06^{\mathrm{a}}$ & $0.19 \pm 0.06^{\mathrm{a}}$ & $0.17 \pm 0.09^{\mathrm{a}}$ & $0.18 \pm 0.08^{\mathrm{a}}$ & $0.17 \pm 0.07^{\mathrm{a}}$ & $0.18 \pm 0.01^{\mathrm{a}}$ & $0.21 \pm 0.02^{\mathrm{a}}$ & $0.16 \pm 0.00^{\mathrm{b}}$ & $0.21 \pm 0.07^{\mathrm{a}}$ & $0.21 \pm 0.06^{\mathrm{a}}$ \\
\hline Behenic acid (C22:0) & $0.10 \pm 0.02^{\mathrm{a}}$ & $0.12 \pm 0.02^{\mathrm{b}}$ & $0.12 \pm 0.05^{\mathrm{c}}$ & $0.11 \pm 0.03^{\mathrm{b}}$ & $0.09 \pm 0.07^{\mathrm{b}}$ & $0.11 \pm 0.07^{\mathrm{c}}$ & $0.11 \pm 0.00^{\mathrm{d}}$ & $0.07 \pm 0.08^{\mathrm{b}}$ & $0.13 \pm 0.04^{b}$ & $0.10 \pm 0.07^{\mathrm{b}}$ \\
\hline $\begin{array}{c}\text { Lignoceric acid } \\
\text { (C24:0) }\end{array}$ & $0.02 \pm 0.02^{\mathrm{a}}$ & $0.01 \pm 0.02^{\mathrm{b}}$ & $0.05 \pm 0.06^{\mathrm{c}}$ & $0.06 \pm 0.04^{\mathrm{d}}$ & $0.09 \pm 0.00^{\mathrm{e}}$ & $0.10 \pm 0.00^{\mathrm{b}}$ & $0.07 \pm 0.00^{\mathrm{f}}$ & $0.06 \pm 0.00^{\mathrm{d}}$ & $0.02 \pm 0.00^{\mathrm{j}}$ & $0.06 \pm 0.00^{\mathrm{d}}$ \\
\hline $\mathrm{C} 18: 1 / \mathrm{C} 18: 2$ & $3.59 \pm 0.14^{\mathrm{a}}$ & $5.07 \pm 0.04^{\mathrm{b}}$ & $2.89 \pm 0.09^{c}$ & $2.88 \pm 0.02^{\mathrm{c}}$ & $2.84 \pm 0.08^{\mathrm{c}}$ & $3.07 \pm 0.04^{\mathrm{d}}$ & $3.07 \pm 0.06^{\mathrm{d}}$ & $2.99 \pm 0.01^{\mathrm{cd}}$ & $3.39 \pm 0.04^{\mathrm{bd}}$ & $3.20 \pm 0.09^{\mathrm{bd}}$ \\
\hline$\sum$ SFAs & $18.37 \pm 0.45^{\mathrm{a}}$ & $21.81 \pm 0.03^{\mathrm{b}}$ & $22.65 \pm 0.00^{\mathrm{c}}$ & $21.93 \pm 0.06^{b c}$ & $22.5 \pm 0.00^{\mathrm{bc}}$ & $22.40 \pm 0.06^{\mathrm{bc}}$ & $21.10 \pm 0.08^{\mathrm{d}}$ & $22.91 \pm 0.06^{\mathrm{e}}$ & $15.89 \pm 0.06^{\mathrm{f}}$ & $21.20 \pm 0.09^{\mathrm{bd}}$ \\
\hline$\sum$ MUFAs & $69.80 \pm 0.08^{\mathrm{a}}$ & $57.70 \pm 0.09^{b}$ & $57.65 \pm 0.05^{\mathrm{b}}$ & $58.08 \pm 0.06^{\mathrm{c}}$ & $57.53 \pm 0.00^{\mathrm{d}}$ & $58.65 \pm 0.04^{\mathrm{e}}$ & $59.62 \pm 0.06^{\mathrm{f}}$ & $57.9 \pm 0.00^{\mathrm{j}}$ & $64.86 \pm 0.08^{\mathrm{h}}$ & $60.25 \pm 0.06^{\mathrm{hi}}$ \\
\hline$\sum$ PUFAs & $19.60 \pm 0.11^{\mathrm{a}}$ & $20.40 \pm 0.01^{\mathrm{b}}$ & $19.68 \pm 0.09^{\mathrm{a}}$ & $19.97 \pm 0.01^{\mathrm{bc}}$ & $19.96 \pm 0.03^{b c}$ & $18.91 \pm 0.04^{\mathrm{d}}$ & $19.25 \pm 0.05^{\mathrm{cd}}$ & $19.14 \pm 0.05^{\mathrm{cd}}$ & $19.34 \pm 0.05^{\mathrm{cd}}$ & $18.68 \pm 0.09^{\mathrm{e}}$ \\
\hline$\sum$ UFAs & $89.40 \pm 0.19^{\mathrm{a}}$ & $78.11 \pm 0.01^{\mathrm{b}}$ & $77.34 \pm 0.04^{\mathrm{c}}$ & $78.05 \pm 0.07^{\mathrm{b}}$ & $77.49 \pm 0.01^{\mathrm{bc}}$ & $77.56 \pm 0.08^{\mathrm{bc}}$ & $78.88 \pm 0.01^{\mathrm{d}}$ & $79.04 \pm 0.05^{\mathrm{e}}$ & $84.21 \pm 0.03^{\mathrm{f}}$ & $78.94 \pm 0.05^{\mathrm{de}}$ \\
\hline$\sum$ MUFAs / $\sum$ PUFAs & $3.56 \pm 0.72^{\mathrm{a}}$ & $2.82 \pm 0.08^{\mathrm{b}}$ & $2.92 \pm 0.08^{\mathrm{c}}$ & $2.90 \pm 0.08^{\mathrm{bc}}$ & $2.88 \pm 0.01^{\mathrm{ab}}$ & $3.10 \pm 0.01^{\mathrm{d}}$ & $3.09 \pm 0.09^{\mathrm{d}}$ & $3.02 \pm 0.04^{\mathrm{d}}$ & $3.35 \pm 0.03^{\mathrm{r}}$ & $3.22 \pm 0.04^{\mathrm{de}}$ \\
\hline
\end{tabular}

SFAs, saturated fatty acids; PUFAs, polyunsaturated fatty acids; MUFAs, monounsaturated fatty acids; UFAs, unsaturated fatty acids. Results were expressed as mean \pm standard deviation of 3 determinations. Different letters for the same line indicate significant differences among varieties $(p<0.05)$.

$\mathrm{S}_{\mathrm{i}}$ : Sample with i means the number of each sample ranged from 1 to 9

$\mathrm{M}_{\mathrm{j}}$ : Microwave treatment time with $\mathrm{j}$ means the microwave treatment time expressed in min

$\mathrm{U}_{\mathrm{k}}$ : Ultrasound treatment time with $\mathrm{k}$ means the ultrasound treatment time expressed in min

S0M0U0 served as a control 


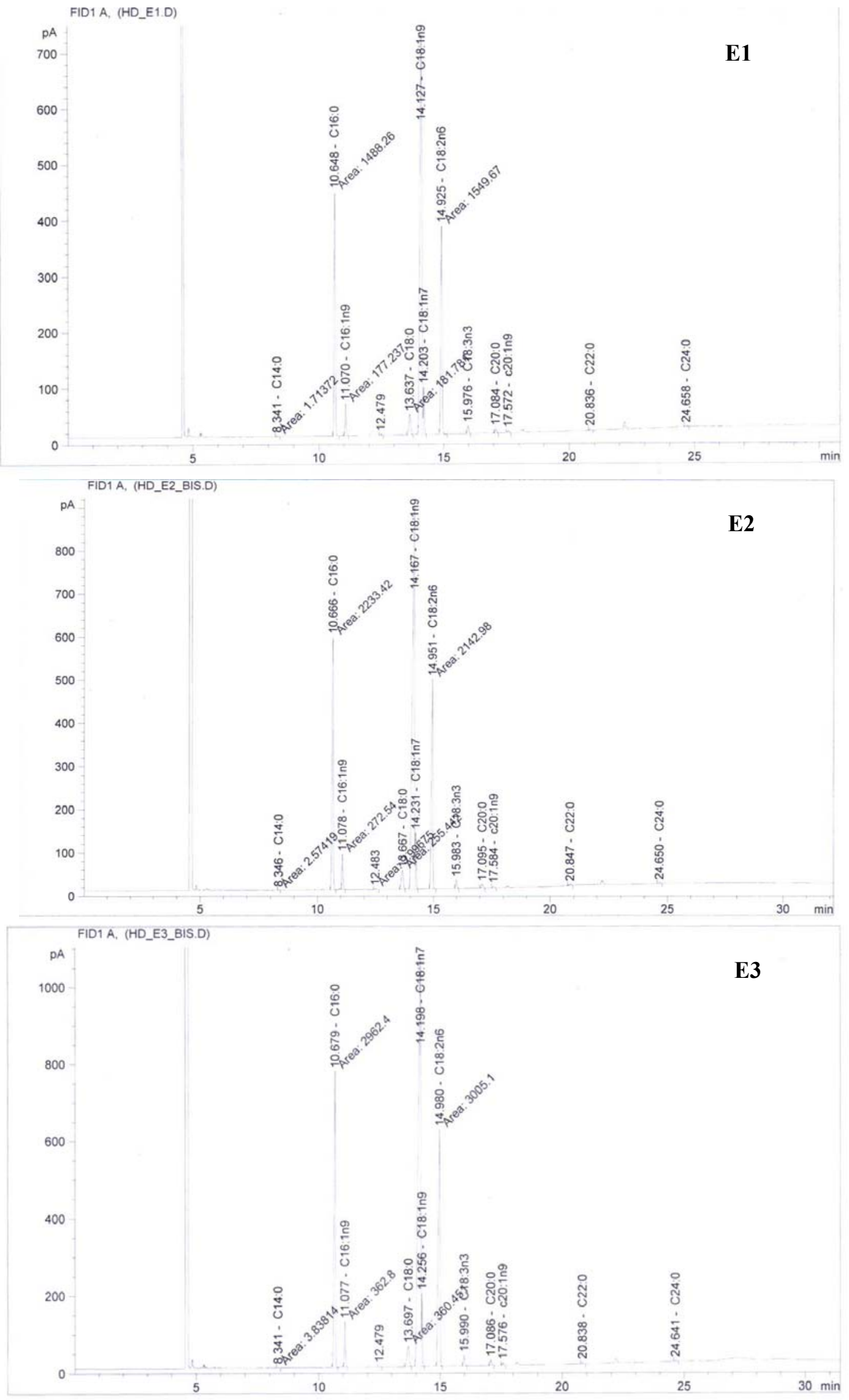




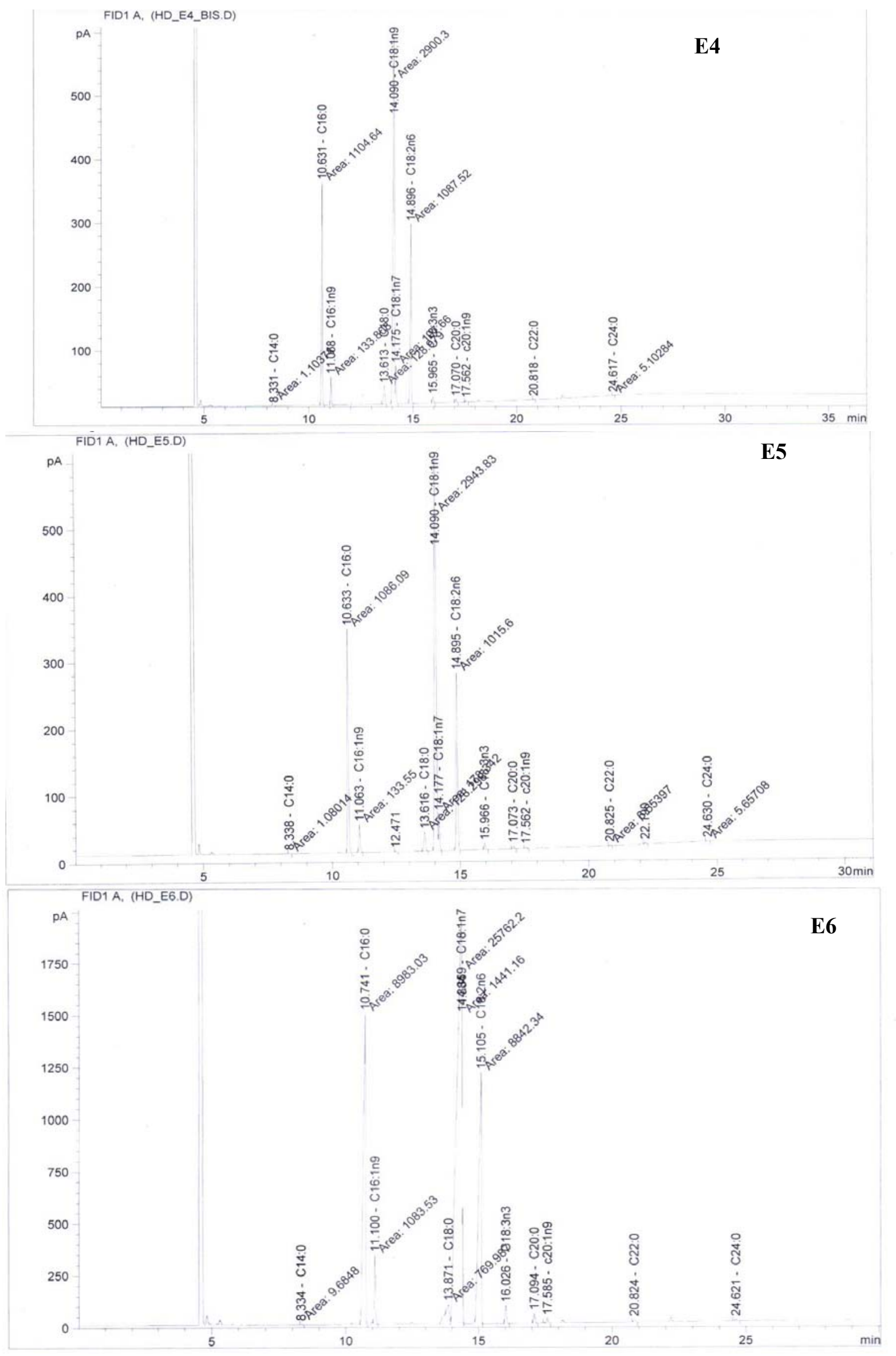




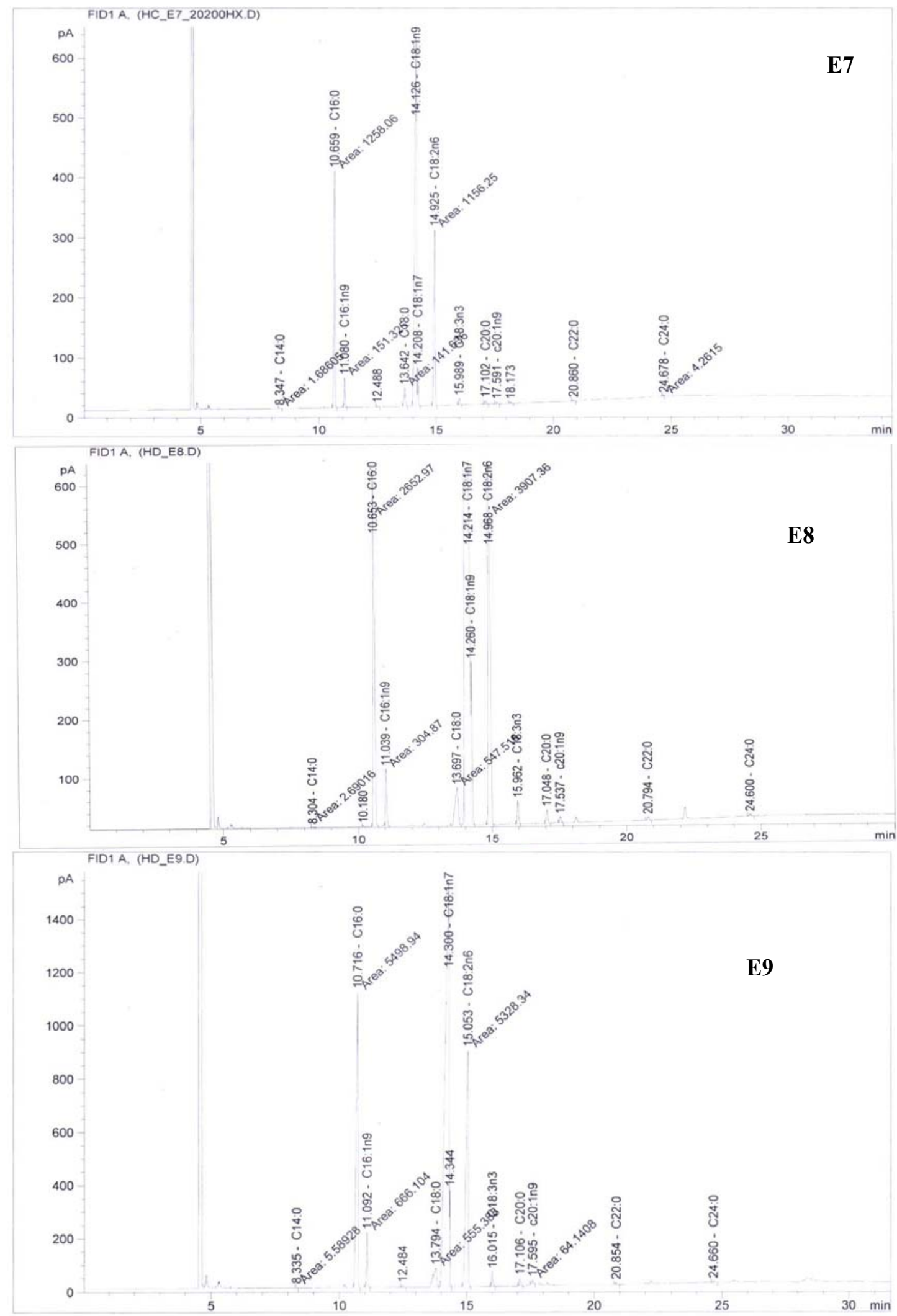

Fig. 1 - GC-FID chromatogramms of the fatty acid profiles of each olive oil extracted from treated olive paste. E1:S1M5U5, E2:S2M5U10, E3:S3M5U15, E4:S4M10U5, E5:S5M10U10, E6:S6M10U15, E7:S7M15U5, E8:S8M15U10, E9:S9M15U15. $S_{i}$ : Sample with i means the number of each sample ranged from 1 to 9

$M_{j}$ : Microwave treatment time with $j$ means the microwave treatment time expressed in min

$U_{k}$ : Ultrasound treatment time with $k$ means the ultrasound treatment time expressed in min 


\section{CONCLUSIONS}

The impact of the combined microwave and ultrasound technologies applied to the olive oil extraction process showed a significant effect on the extra virgin olive oil quality parameters as well as fatty acids profile and phenolic content for the tests conducted on Chemali olives. The results obtained in this study have revealed that the highest phenolic content was obtained after olive paste treatment with microwave for $15 \mathrm{~min}$ followed by $15 \mathrm{~min}$ of ultrasound treatment. In addition, and taking into account the oil quality, the use of combination treatments between these two technologies, may improve the quality indices, stability as well as the fatty acid composition of the obtained oils. Based on these findings, it was believed that contribute to the outcome of the industrialists, especially olive oil producer in our country.

Acknowledgements. The authors thank the Tunisian Ministry of Higher Education and Scientific Research for financial support and to Professor Mohamed Rigane who revised the English language.

\section{REFERENCES}

1. N. Rahmanian, S. Jafari and T. Wani, Trends Food Sci. Technol., 2015, 42, 150.

2. F. Le Floch, M. Tena, A. Ríos and M. Valcárcel, Talanta, 1998, 46, 1123.

3. M. Ahmad-Qasem, E. Barrajón-Catalán, V. Micol, A. Mulet and J. García-Pérez, Food Res. Inter., 2013, 50, 189.

4. A. Yahyaoui, G. Rigane, S. Mnif, R. Ben Salem, A. Acar and D. Derya Arslan, Eur. J. Lipid Sci. Tech., 2019, 121, 1800295.

5. M. Chira, G. Rigane, C. Calas-Blanchard, R. Rouillon and R. Ben Salem, Rev. Roum. Chim., 2020, 65, 179.

6. A. Tamborrino, R. Romaniello, R. Zagaria and A. Leone, Biosyst. Eng., 2014, 127, 92.

7. G. Veneziani, S. Esposto, A. Taticchi, R. Selvaggini, B. Sordini, A. Lorefice, L. Daidone, M. Pagano, R.
Tomasone and M. Servili., Front. Nutr., 2019, doi: 10.3389/fnut.2019.00134.

8. A. Gila, A. Sanchez-Ortiz, A. Jimenez and G. Beltran, Ultrason. Sonochem., 2020, 70, 105320.

9. A. Leone, R. Romaniello, A. Tamborrino, S. Urbani, M. Servili, M. Amarillo and P. Juliano, Eur. J. Lipid Sci. Tech., 2018, 120, 1700261.

10. R. Malheiro, I. Oliveira, M. Vilas-Boas, S. Falcão, A. Bento and J. A. Pereira, Food Chem. Toxicol., 2009, 47, 92.

11. A. Leone, A. Tamborrino, R. Zagaria, E. Sabella and R. Romaniello., J. Food Eng., 2015, 146, 44.

12. D. Boskou, "Olive Oil: Chemistry and Technology", AOCS Press, Champaign, IL 1986, p. 85.

13. G. Rigane, J. Jebali, H. Gazghazi, H. Riguene, M. L. Khouja and R. Ben Salem, Rev. Roum. Chim., 2019, 64, 999.

14. International Olive Oil Council. RES. COI/T.15/NC 1 (2003).

15. M. I. Minguez-Mosquera, B. Gandul-Roja and L. Gallardo Guerrero, J. Agric. Food Chem., 1991, 40, 60-63.

16. European Union Commission Regulation (EEC), 2568/1991, OJEC, 1991, L 248.

17. G. Rigane, R. Ben Salem, S. Sayadi and M. Bouaziz, J. Food Sci., 2011, 76, C965.

18. M. A. Baldo, P. Oliveri, R. Simonetti and S. Daniele, Talanta., 2016, 161, 881 .

19. European Union Commission Regulation (EEC) 1989/2003, OJEC. 295, 57.

20. G. Rigane, A. Yahyaoui, A. Acar, S. Mnif, R. B. Salem and D. Arslan, Biotechnol. Rep., 2020 e00442.

21. A. Jimenez, G. Beltran and M. Uceda., Ultrason. Sonochem, 2007, 14, 725 .

22. M.L. Clodoveo, D. Viviana, L.N. Domenico, P. Rossana and G. Giuseppe, Eur. J. Lipid Sci. Tech., 2013, 115, 1062.

23. G. Rigane, M. Boukhris, M. Bouaziz, S. Sayadi and R. Ben Salem, J. Sci. Food Agric., 2013, 93, 1242.

24. S. Dabbou, F. Brahmi, F. Taamali, M. Issaoui, Y. Ouni, Y. Braham, M. Zarrouk and M. Hammami., J. Am. Oil Chem. Soc., 2010, 87, 1199.

25. A. Lazzez, M. Cossentini, M. Khlif and B. Karray, J. Soc. Chim. Tun., 2006, 8,21

26. I. Oueslati, C. Anniva, D. Daoud, M.Z. Tsimidou and M. Zarrouk, Food Chem., 2009, 112, 733.

27. L. Di Giovacchino, S. Sestili and D. Di Vincenzo, Eur. J. Lipid Sci. Tech., 2002, 104, 587.

28. A.K. Kiritsakis, G.D. Nanos, Z. Polymenoupoulos, T. Thomai, and E.Y. Sfakiotakis, J. Am. Oil Chem. Soc., 1998, 75,724 . 
